\title{
A Role for Nuclear PTEN in Neuronal Differentiation
}

\author{
Mahesh B. Lachyankar, ${ }^{1}$ Nazneen Sultana, ${ }^{1}$ Christopher M. Schonhoff, ${ }^{2}$ Prasenjit Mitra, ${ }^{1}$ Wojciech Poluha, ${ }^{1}$ \\ Stephen Lambert, ${ }^{3}$ Peter J. Quesenberry, ${ }^{4}$ N. Scott Litofsky, ${ }^{5}$ Lawrence D. Recht, ${ }^{6}$ Roya Nabi, ${ }^{7}$ \\ Susan J. Miller, ${ }^{8}$ Shinji Ohta, ${ }^{8}$ Benjamin G. Neel, ${ }^{8}$ and Alonzo H. Ross ${ }^{1}$ \\ Departments of ${ }^{1}$ Pharmacology and Molecular Toxicology, ${ }^{2}$ Biochemistry and Molecular Biology, ${ }^{3}$ Cell Biology, ${ }^{4}$ Medicine \\ (Cancer Center), 5 Surgery, and 6 Neurology, University of Massachusetts Medical School, Worcester, Massachusetts \\ 01655, 7Department of Biology and Biotechnology, Worcester Polytechnic Institute, Worcester, Massachusetts 01609, \\ and ${ }^{8}$ Cancer Biology Program, Division of Hematology-Oncology, Department of Medicine, Beth Israel-Deaconess \\ Medical Center, Boston, Massachusetts 02215
}

\begin{abstract}
Mutations of phosphatase and tensin homolog deleted on chromosome 10 (PTEN), a protein and lipid phosphatase, have been associated with gliomas, macrocephaly, and mental deficiencies. We have assessed PTEN's role in the nervous system and find that PTEN is expressed in mouse brain late in development, starting at approximately postnatal day 0 . In adult brain, PTEN is preferentially expressed in neurons and is especially evident in Purkinje neurons, olfactory mitral neurons, and large pyramidal neurons. To analyze the function of PTEN in neuronal differentiation, we used two well established model systemspheochromocytoma cells and cultured CNS stem cells. PTEN is expressed during neurotrophin-induced differentiation and is
\end{abstract}

detected in both the nucleus and cytoplasm. Suppression of PTEN levels with antisense oligonucleotides does not block initiation of neuronal differentiation. Instead, PTEN antisense leads to death of the resulting, immature neurons, probably during neurite extension. In contrast, PTEN is not required for astrocytic differentiation. These observations indicate that PTEN acts at multiple sites in the cell, regulating the transition of differentiating neuroblasts to postmitotic neurons.

Key words: phosphatase; phosphatidylinositol phosphate; nerve growth factor; PC12 cells; stem cells; brain-derived neurotrophic factor; neurite extension
A tumor suppressor on human chromosome 10 plays a major role in the development of highly malignant and deadly gliomas. Recently this tumor suppressor was cloned and is now known as phosphatase and tensin homolog deleted on chromosome 10 (PTEN; also MMAC1 and TEP1) (Li and Sun, 1997; Li et al., 1997; Steck et al., 1997). Germline mutations of PTEN result in Cowden disease, Bannayan-Zonana syndrome, and LhermitteDuclos disease in which disorganized benign tumors appear in multiple organs. In addition, some patients show defects in neural development such as macrocephaly, mental retardation, cerebellar hypertrophy, ataxia, and seizures (Gorlin et al., 1992; Eng et al., 1994; Liaw et al., 1997). Although the importance of PTEN in cancer etiology is clear, PTEN's function in the nervous system is not yet known.

PTEN encodes a phosphatase with a tensin-like domain at the $\mathrm{N}$ terminal and a novel domain of unknown function at the $\mathrm{C}$ terminal (Li and Sun, 1997; Li et al., 1997; Steck et al., 1997). This protein is highly conserved across species lines with only a single

\footnotetext{
Received Oct. 11, 1999; revised Nov. 17, 1999; accepted Nov. 24, 1999.

This work was supported by the Our Danny Fund (University of Massachusetts Cancer Center) and National Institutes of Health Grants NS21716, CA68426, and NS28760. We thank Delia Demers and Stephen Jones for their help in preparing the antiserum, Kui Lei for help with the initial nuclear experiments, Tom Schoenfeld for use of the cryostat, and Hans Kusters, Jeanne Lawrence, and John McNeil for help with microscopy. Chiffon Wu and Rebecca Salmonsen provided technical support. We are grateful to Jing Li for PTEN plasmids, Amgen (Thousand Oaks, CA) and Regeneron for recombinant BDNF, and Wayne Zhou for a sample of PTEN recombinant protein. Zuoshang $\mathrm{Xu}$ and Charles Sagerstrom provided critical reading of this manuscript.

Correspondence should be addressed to Dr. Alonzo H. Ross, Department of Pharmacology and Molecular Toxicology, Room S7-147, University of Massachusetts Medical School, 55 Lake Avenue North, Worcester, MA 01655. E-mail: Alonzo.Ross@UMASSMED.EDU.

Copyright (C) 2000 Society for Neuroscience $\quad 0270-6474 / 00 / 201404-10 \$ 15.00 / 0$
}

amino acid difference between human and mouse-a Ser-Thr exchange. The PTEN enzyme is a dual-specificity protein phosphatase (Myers et al., 1997) and a phosphatidylinositol phosphate (PIP) phosphatase (Maehama and Dixon, 1998). The PIP activity is specific for the 3-position of the inositol ring.

PTEN may play multiple biological roles. PTEN and phosphoinositide-3 kinase have opposing effects on PIP levels and, consequently, opposing effects on cell proliferation and survival (Datta et al., 1997; Furnari et al., 1998; Myers et al., 1998). PTEN inhibits cell migration, spreading, and focal adhesion formation by dephosphorylating the focal adhesion kinase (Tamura et al., 1998). PTEN also inhibits activation of the mitogenactivated protein (MAP) kinase pathway (Gu et al., 1998). Mice lacking PTEN show overgrowth of the cephalic and caudal regions and are embryonic lethal (Di Cristofano et al., 1998; Stambolic et al., 1998; Suzuki et al., 1998). Heterozygous PTEN mice are viable but have an autoimmune disorder, defective Fasmediated apoptosis, and an abnormally high rate of cancer (Di Cristofano et al., 1999). These findings verify the identification of $P T E N$ as a tumor suppressor and demonstrate the quantitative requirement for PTEN phosphatase.

The mutation of PTEN in gliomas, the prevalence of neurological defects in patients with mutated PTEN, and the growing recognition of PIPs as neuronal regulators led us to assess the role of PTEN in the nervous system. PTEN is expressed in mouse brain late in development, starting at approximately postnatal day 0 (P0). In adult mouse brain, PTEN is preferentially expressed in neurons and is especially evident in Purkinje neurons, olfactory mitral neurons, and large pyramidal neurons. PTEN is expressed during neurotrophin-induced differentiation of cultured cells and 
is detected in both the nucleus and cytoplasm. Using antisense oligonucleotides, we find that suppression of PTEN expression during neurotrophin-induced differentiation of pheochromocytoma (PC12) cells and CNS stem cell cultures (Reynolds et al., 1992) leads to decreased yields of neuronal cells. In contrast, suppression of PTEN expression does not affect the yield of glial cells. For PC12 cells, we determined that PTEN antisense did not block initiation of differentiation. Instead it decreased survival of differentiating cells. These results suggest a prominent role of PTEN in neuronal maturation and adult neuronal function.

\section{MATERIALS AND METHODS}

Anti-PTEN antisera. The sequences corresponding to human PTEN amino acids 1-141 and 142-403 were PCR amplified from expressed sequence tags 264611 and 365465, respectively, from Jing Li (Columbia University) and cloned into the EcoRI-HindIII sites of expression vector pGEMEX-2 (Clontech) to yield plasmids pL2-9 and pL3-4. The T7 bacteriophage gene 10-PTEN fusion proteins were expressed in Escherichia coli BL21 (DE3) and were purified from inclusion bodies. Rabbit serum albumin (RSA) was activated with $1.9 \%$ glutaraldehyde for $9 \mathrm{hr}$ at $4^{\circ} \mathrm{C}$, dialyzed, mixed with PTEN fusion protein ( $2 \mathrm{mg}$ of RSA to $1 \mathrm{mg}$ of fusion protein), and dialyzed against PBS. Rabbits were immunized with the RSA-coupled fusion protein (300 $\mu \mathrm{g}$ per rabbit) suspended in complete Freund's adjuvant. Rabbits were boosted with RSA-fusion protein (150 $\mu \mathrm{g}$ per rabbit) in incomplete Freund's adjuvant. The antiserum prepared against the L2-9 fusion protein was not effective and was not further characterized.

Fusion proteins were coupled to cyanogen bromide-Sepharose in $4 \mathrm{M}$

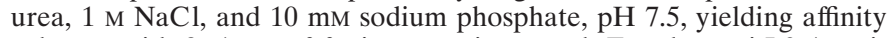
columns with 2-4 mg of fusion protein per ml. For the anti-L3-4 antiserum, anti-gene 10 antibodies were eliminated by passing the antiserum through a Sepharose column containing the L2-9 fusion protein. The flowthrough was passed over a Sepharose column containing the L3-4 fusion protein. The column was washed with low- and high-salt buffers, and specific anti-PTEN antibodies were eluted with $4 \mathrm{M} \mathrm{MgCl}_{2}$. These antibodies were extensively dialyzed and then stored in PBS/glycerol $(1: 1, \mathrm{v} / \mathrm{v})$ at $-20^{\circ} \mathrm{C}$.

Although not shown, we used two anti-GST-PTEN antisera to verify these results. The first was prepared using standard procedures. The second was purchased from Upstate Biochemicals.

Cell culture. CNS stem cell cultures, known as neurospheres (Reynolds and Weiss, 1992), were grown from striata of embryonic day 15 (E15) mouse embryos. Cells from passages 1-4 were plated on plastic ware coated with E-C-L cell attachment matrix (Upstate Biotechnology, Lake Placid, NY), an extracellular matrix preparation derived from Englebreth-Holm-Swarm mouse tumors, containing entactin, collagen IV, and laminin, and differentiated with nerve growth factor (NGF) or human recombinant brain-derived neurotrophic factor (BDNF) (Lachyankar et al., 1997).

The PC12 line was grown in DMEM supplemented with $10 \%$ horse serum, 5\% fetal bovine serum, and $100 \mu \mathrm{g} / \mathrm{ml}$ gentamycin. For differentiation experiments, cells were plated on collagen-poly-D-lysine-coated plasticware or E-C-L-coated plasticware in either the same serumcontaining medium or defined medium (Reinhold and Neet, 1989). Fresh medium and NGF (100 ng/ml; Harlan, Indianapolis, IN) were added every 48 hr. PC12/WAF1 cells (Poluha et al., 1997) were grown in the presence of $100 \mu \mathrm{g} / \mathrm{ml} \mathrm{G} 418$ and $125 \mu \mathrm{g} / \mathrm{ml}$ hygromycin. Expression of p $21^{\text {WAF1 }}$ was induced by adding $25 \mathrm{~mm}$ isopropyl $\beta$-D-thiogalactopyranoside to the medium either $24 \mathrm{hr}$ before the addition of NGF or at the same time.

Transfection. The PTEN expression vector pcDNA3-PTEN was derived from the pcDNA3 plasmid (Invitrogen, Carlsbad, CA) and includes a hemagglutinin (HA) tag at the $\mathrm{N}$ terminal and the entire coding sequence of human PTEN. The sequence of the insert was verified by automated DNA sequencing. For transfection, PC12 cells were seeded on poly-D-lysine-coated coverslips (12 $\mathrm{mm}$ diameter) and allowed to adhere overnight. The plasmid and Fugene 6 (Boehringer Mannheim, Indianapolis, IN) were mixed in DMEM according to the manufacturer's instructions and then applied to the cells, using $2 \mu \mathrm{g}$ of DNA and $6 \mu \mathrm{l}$ of Fugene 6 per coverslip. The cells were analyzed $60 \mathrm{hr}$ after transfection.

Antisense treatment. For these studies, we followed accepted procedures for the use of antisense oligonucleotides (Stein, 1996). We included multiple antisense and control oligonucleotides, used low concentrations of oligonucleotides with cationic detergents to enhance oligonucleotide delivery, and avoided oligonucleotides with G-quartets. Two PTEN antisense phosphorothioate oligonucleotides AS1 [5'-GCT CAA CTC TCA AAC TTC CAT-3'; 43\% GC; corresponds to nucleotides 217-237 (Steck et al., 1997)] and AS2 (5'-GCC GCC GCC GTC TCT CAT CTC-3'; 71\% GC; corresponds to nucleotides 269-289) and three control phosphorothioate oligonucleotides Con18 (5'-TGG ATC CGA CAT GTC AGA-3'; 50\% GC), Con21 (5'-ATG GAA GTT TGA GAG AGT TGA-3'; 38\% GC), and ConS (5'-GAG ATG AGA GAC GGC GGC GGC-3'; 71\% GC) were obtained from Oligos Etc. (Wilsonville, OR). ConS is the sense oligonucleotide for AS2. These oligonucleotides were mixed with the cationic detergent Lipofectin, diluted with medium, and used to treat cells at $1 \mu \mathrm{M}$ oligonucleotide as described in our previous publication (Poluha et al., 1996).

Immunostaining. Fresh neonatal or adult mouse brain was frozen in Tissuetek, and 6-10 $\mu \mathrm{m}$ sections were cut with a cryostat. Sections were fixed in methanol $\left(-20^{\circ} \mathrm{C}\right)$ for $10 \mathrm{~min}$, washed, and blocked with $0.1 \%$ BSA in PBS. The sections were sequentially incubated with primary antibody (1 hr), the biotinylated secondary avidin-biotin complex (Vector Laboratories, Burlingame, CA), and diaminobenzidine substrate (Sigma, St. Louis, MO). After washing, sections were counterstained with methyl green and mounted in Permount (Fluka, Buchs, Switzerland). For immunostaining of cultured cells, cells were fixed for $10 \mathrm{~min}$ with methanol $\left(-20^{\circ} \mathrm{C}\right)$. After washing with PBS, cells were blocked with $0.1 \%$ BSA. Cells were stained with a rhodamine- or fluoresceinconjugated secondary antibody and mounted in Vectashield (Vector Laboratories).

SMI312 from Sternberger Monoclonals (Baltimore, MD) is a cocktail of monoclonal antibodies directed against phosphorylated epitopes on neurofilament (NF) subunits $\mathrm{M}$ and $\mathrm{H}$. Anti- $\beta$-tubulin III monoclonal antibody was from Sigma. Anti-HA tag monoclonal antibody 16B12 was from Babco (Richmond, CA). Anti-GalC and -GFAP monoclonal antibodies were from Boehringer Mannheim. Anti- $\beta$-tubulin monoclonal antibodies were from Sigma and Boehringer Mannheim and gave similar results. Anti-p27 ${ }^{\mathrm{Kip} 1}$ monoclonal antibody was from Santa Cruz Biotechnology (Santa Cruz, CA). Secondary antibodies were from Jackson ImmunoResearch (West Grove, PA).

Western blotting and subcellular fractionation. Rat or mouse tissues were collected on dry ice and extracted with Triton X-100 lysis buffer (1\% Triton X-100, $137 \mathrm{~mm} \mathrm{NaCl}, 2$ mm EDTA, 1 mm PMSF, $10 \mathrm{~mm} \mathrm{NaF}$, $5 \mu \mathrm{g} / \mathrm{ml}$ aprotinin, and $20 \mathrm{~mm}$ Tris, $\mathrm{pH}$ 7.5). The tissues were dispersed with a Dounce homogenizer at $4^{\circ} \mathrm{C}$. Cultured cells were extracted with the same buffer. These samples $(50 \mu \mathrm{g}$ of protein per sample) were separated by SDS-PAGE (10\% gel), and proteins were electrotransferred to Immobilion P (Millipore, Bedford, MA). These filters were blocked with $5 \%$ powdered milk, and immunoreactive bands were detected by chemiluminescence.

Nuclear and cytosolic fractions were prepared from PC12 cells and CNS stem cells (Ohmori et al., 1997). The resulting fractions were normalized by the Bio-Rad dye-binding protein assay and analyzed by Western blotting (50 $\mu \mathrm{g}$ of protein per sample).

\section{RESULTS}

\section{Expression of PTEN in the CNS}

We first analyzed the expression of PTEN in adult mouse brain. Western blotting of total brain extracts shows a single band with an apparent molecular weight of $\sim 60,000 \mathrm{Da}$ (Fig. 1), consistent with reports from other laboratories (Li and Sun, 1997; Stambolic et al., 1998). The PTEN band was not detected in E15 brain but was detected in samples from P0 and later stages of development. In this particular experiment, PTEN expression was slightly less for adult than for newborns. This difference was not consistently observed in other experiments. The developmental time course of PTEN was similar to that of neurofilament (Fig. 1), which dramatically increases postnatally (Shaw and Weber, 1982).

In these studies, we used a new anti-PTEN antibody, and hence, questions of specificity are critical. We used affinitypurified antibody and did not observe the PTEN band in immunoblots lacking primary antibody or using a preimmune antiserum. Although not shown, all immunoblots were reproduced using an independent anti-GST-PTEN antiserum (see Materials 


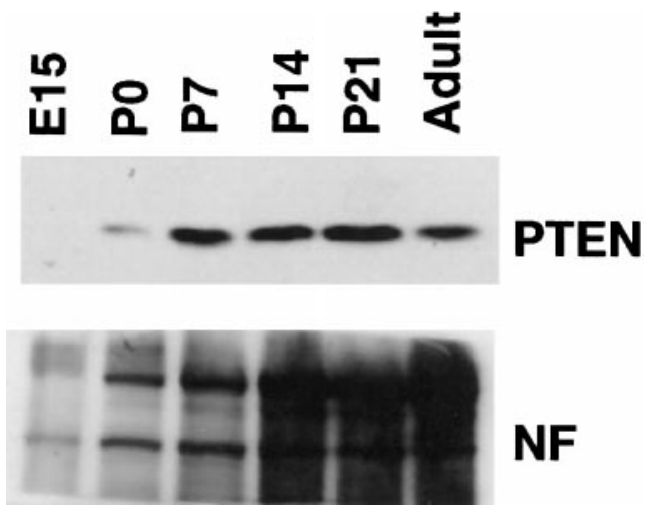

Figure 1. Expression of PTEN in mouse brain. Western blot showing developmental time course of PTEN and phosphorylated neurofilament.

and Methods). In addition, some of the blots were repeated with a commercial anti-GST-PTEN antiserum that became available as we were completing these studies. The results for all three antibodies were similar. Finally, as will be described below, cells treated with PTEN antisense oligonucleotides yielded a much less intense PTEN band by Western blotting.

To identify the PTEN-expressing cells, we sectioned, fixed, and immunostained adult mouse brains for PTEN. Strong immunostaining was observed in the cortex and cerebellum, but little reactivity was detected in the brainstem. Specific examples of PTEN immunostaining are shown in Figure 2. In the olfactory bulb (Fig. $2 A-C$ ), mitral cells gave the strongest immunostaining (Fig. 2B). There was weaker staining of periglomerular cells (Fig. $2 C$ ) and very little staining in the internal and external plexiform layers. Hippocampal neurons (Fig. 2D-F) showed strong staining in all regions. In the cerebellum (Fig. $2 G-I$ ), Purkinje cells were strongly positive. The scant cytoplasm of neurons in the internal granular layer was positive. The molecular layer showed only stellate and basket interneurons weakly positive. There was no staining of dendrites evident in the molecular layer. Finally, PTEN expression was not detected in white matter tracts of the cerebellum (Fig. 2J,*), even though staining of similar sections shows GFAP-positive astrocytes (Fig. 2L) and GalC-positive oligodendrocytes (data not shown). Detailed examination of the corpus callosum (Fig. $2 K$ ) also did not reveal PTEN expression for glial cells. Neurons of the amygdala (Fig. $2 K$, right edge) were PTEN positive.

In summary, PTEN-positive neurons were detected in many sites, including mitral, periglomerular, and granule neurons in the olfactory bulb, pyramidal neurons in the cortex, magnocellular neurons in the basal forebrain, hippocampal and amygdalar neurons, and cerebellar Purkinje and granule neurons. Immunostaining was most evident for large neurons and apparently was confined to the cell bodies. We did not observe staining of processes.

Specificity of the immunostaining was confirmed by a number of controls. Staining was not evident when primary antibody was omitted or a preimmune antiserum was used. Multiple secondary antibodies were tested, all yielding similar results. In addition, all experiments were repeated with an independent anti-PTEN antiserum, and some of these experiments were repeated with a commercial antiserum (data not shown). Similar results were obtained with each of these antibodies.

\section{PTEN and PC12 cells}

On the basis of our observations of neuronal PTEN, we analyzed the well characterized neuronal differentiation model PC12.
NGF-treated PC12 cells were reported previously to express PTEN mRNA (Li and Sun, 1997). Treatment of PC12 cells with NGF induced expression of PTEN protein, although expression of PTEN lagged behind neurite extension (Fig. 3).

For differentiating PC12 cells, PTEN was most evident in speckles in the nucleus with only a faint diffuse staining in the cytoplasm (Fig. 4A,B). In contrast, more mature PC12 cells (Fig. $4 C, D$ ) showed strong staining of both the cytoplasm and nucleus. This staining was judged specific because no staining was observed for preimmune antisera. In addition, including the L3-4 fusion protein $(15 \mu \mathrm{g} / \mathrm{ml})$ with the anti-PTEN primary antibody markedly reduced staining as well as Western blot intensity (data not shown). The L2-9 fusion protein did not diminish staining or blot intensity.

To verify the nuclear localization, we treated PC12 cells with NGF for $6 \mathrm{~d}$ and subjected the cells to subcellular fractionation. PTEN was detected by Western blotting in both the cytosolic and the nuclear fractions (Fig. $4 E$ ). The nuclear fraction contained $\mathrm{p} 27^{\mathrm{Kip} 1}$, a nuclear marker, but had very little $\beta$-tubulin, and hence, these nuclear fractions were primarily free of cytosolic contamination. In addition, PC12 cells were transfected with an epitope-tagged PTEN and stained with anti-HA antibody. The recombinant protein was detected in speckles in the nuclei (Fig. $4 F$ ), similar to endogenous PTEN. This immunostaining was specific, because no nuclear speckles were detected if anti-HA antiserum was omitted or if PC12 cells without plasmid or PC12 cells transfected with pcDNA3 plasmid lacking the insert were used (data not shown). Hence, by several independent approaches, we have demonstrated nuclear PTEN. This nuclear localization of PTEN is novel and suggests new regulatory functions for PTEN.

We next used antisense oligonucleotides to test the requirement for PTEN in neuronal differentiation. To enhance the stability of the oligonucleotides, we used defined medium (Reinhold and Neet, 1989), which increases the rate of differentiation (Gollapudi and Neet, 1997). Under these conditions, NGF induction of PTEN also was much more rapid (Fig. 5A). PTEN was detected after $1 \mathrm{~d}$ of treatment, whereas 4-6 d was required in the presence of serum (Fig. 3). In these experiments, we observed the 60,000 Da PTEN band and, in addition, a less intense 40,000 Da band (Fig. 5A, *). We believe that the second band is a proteolytic product, because as cell extracts aged, the 60,000 Da band became weaker and the 40,000 Da band appeared.

Addition of PTEN antisense oligonucleotide AS1 or AS2 reduced the yield of both total cells and cells with neurites (Fig. 5B). Control oligonucleotides Con18, Con21, and ConS had no apparent effect. Furthermore, the two PTEN antisense oligonucleotides, but not the control oligonucleotides, lowered PTEN levels (Fig. 5C). The rate of differentiation and subsequent cell death varied somewhat from experiment to experiment. In this particular experiment (Fig. 5C), samples were collected at $40 \mathrm{hr}$ of treatment as the morphological changes began and before substantial cell loss. Antisense oligonucleotides inhibited PTEN expression from 70 to $100 \%$ with no detectable PTEN in three of nine samples. In this experiment, a control with no oligonucleotide was not included. However, in experiments not shown, there was no difference in PTEN expression between cells with no oligonucleotide and cells with control oligonucleotide. A parallel immunoblot made with anti- $\beta$-tubulin showed no effect of antisense oligonucleotides (Fig. 5C) and confirmed the specificity of the antisense oligonucleotides. Hence, the PTEN antisense oli- 

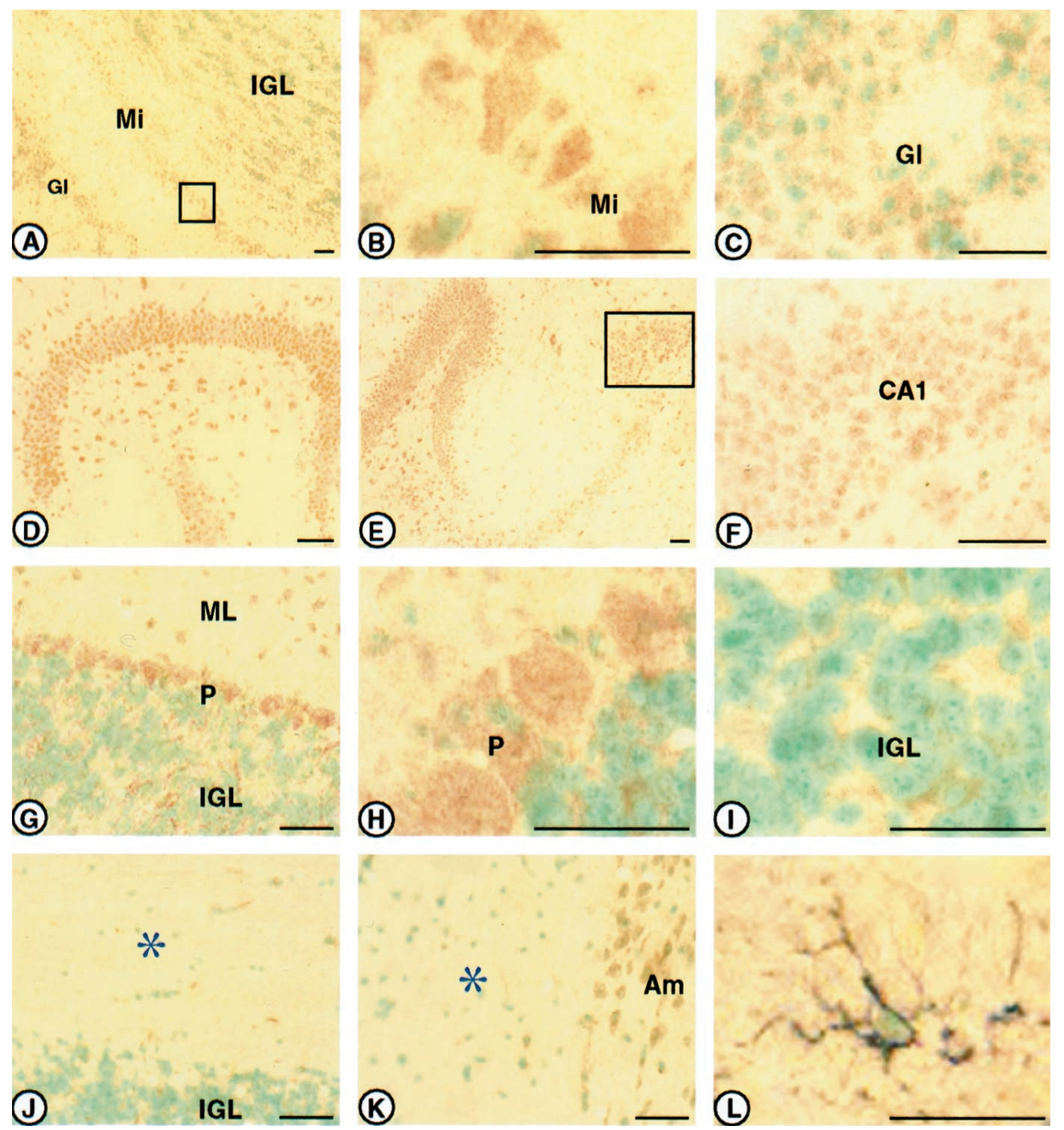

\section{$\oplus$}
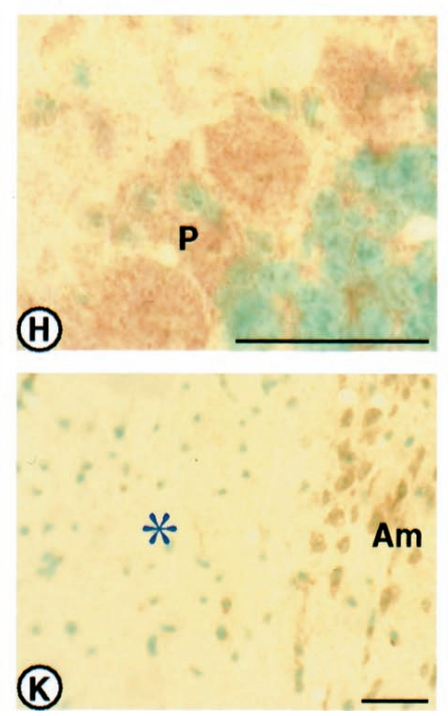
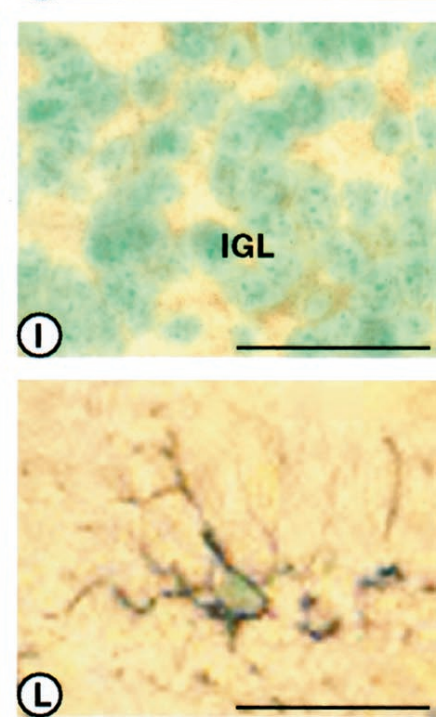

Figure 2. Neurons but not astrocytes or oligodendrocytes express PTEN. $A$, Olfactory bulb including glomeruli $(G l)$, mitral cells $(M i)$, and the inner granule layer $(I G L)$. B, Higher magnification view of mitral cells. $C$, Small PTEN-positive periglomerular cells. $D-F$, PTEN staining in all regions of the hippocampus with higher magnification of CA1 $(F) . G$, Cerebellum showing weak staining of the internal granule layer $(I G L)$, strong staining of Purkinje cells $(P)$, and occasional positive cells in the molecular layer $(M L)$. There was no staining of dendrites evident in the $M L$. H, Higher magnification of Purkinje cells. I, Higher magnification of the IGL showing staining in the cytoplasm. $J$, White matter tracts in the cerebellum marked by an *. $K$, Corpus callosum $(*)$ with PTEN-positive amygdala $(A m)$ at the right edge. $L$, Higher magnification of a doublestained astrocytic cell (PTEN, red brown; GFAP, blue gray) from white matter tracts of the cerebellum. All sections were counterstained with methyl green. Scale bars, $20 \mu \mathrm{m}$. gonucleotide specifically decreased the survival of differentiating PC12 cells.

The particular stage at which cell loss occurred was analyzed. In the presence of either antisense or control oligonucleotides, differentiation began apparently normally with cells flattening and extending short neurites (Fig. 5D, 1-2 cell diameters long) in the first $10-20 \mathrm{hr}$ of NGF treatment. For PC12 cells treated with control oligonucleotides, neuronal differentiation proceeded with elongation of the short neurites, yielding cells with neurites 3 or more cell diameters long (Fig. 5E). However, PC12 cells in the presence of PTEN antisense oligonucleotides failed to produce long neurites (Fig. 5E). Instead, the cells detached from the substratum (Fig. $5 F$ ). It appears that they underwent apoptosis, as judged by the presence of apoptotic bodies in DAPI-stained nuclei (data not shown). In contrast, control oligonucleotides did not induce death of differentiating PC12 cells (Fig. 5F). Also, addition of the PTEN antisense oligonucleotides to untreated (-NGF) PC12 cells had no apparent effect (data not shown), consistent with the lack of PTEN expression in untreated PC12 cells. In this experiment, the untreated (-NGF) and the differentiating (+NGF) PC12 cells were cultured with the same substratum and defined medium. These results demonstrate that PTEN is required not for initiation of differentiation but rather for survival of differentiating PC12 cells.

\section{CNS stem cells and PTEN}

CNS stem cells from fetal striatum can be grown in serum-free medium, using epidermal growth factor (EGF) as a mitogen (Reynolds et al., 1992). These cells grow as large clusters and are known as neurospheres. Culturing these neurosphere cells with NGF or BDNF in the absence of EGF results in a mix of neurons and astrocytes (Ahmed et al., 1995; Lachyankar et al., 1997). Proliferating CNS stem cells in the presence of EGF did not express PTEN (data not shown), but PTEN was present in the nucleus and possibly in the cytoplasm of neurons differentiating in the presence of BDNF (Fig. $6 A-C, 6 \mathrm{~d}$ of BDNF treatment). In more mature neuronal cells (14 $\mathrm{d}$ of BDNF treatment), expression of PTEN was stronger and was detected, apparently, throughout the cell (Fig. 6D-F). Low levels of nuclear PTEN were observed for immature astrocytes (Fig. 6G-I) but not for mature astrocytes (Fig. $6 J-L$ ). Induction of PTEN by BDNF was confirmed by Western blotting (Fig. 6M). Because EGF was omitted from these cultures, the + BDNF cultures contained astrocytes and neurons, whereas the $-\mathrm{BDNF}$ cultures contained primarily astrocytes. Consistent with the immunofluorescence microscopy, PTEN levels were greater in the neuron-containing + BDNF cultures than in the astrocyte-containing - BDNF cultures (Fig. 6M). 

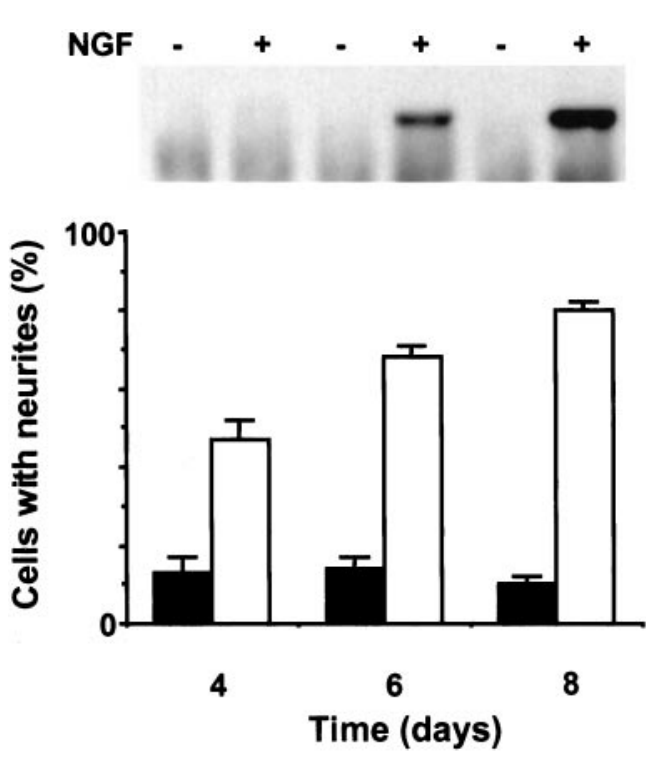

Figure 3. NGF induces PTEN expression for PC12 cells. Time course of NGF-induced neurite extension (bottom) and PTEN expression (top). PC12 cells were treated with (open bars) or without ( filled bars) NGF (100 $\mathrm{ng} / \mathrm{ml}$ ). The percentages of cells with neurites at least 5 cell diameters long ( \pm SEM) are shown. PTEN expression was assessed by Western blotting.

CNS stem cells were cultured for $6 \mathrm{~d}$ with BDNF, thereby inducing PTEN-positive neuronal and astroglial cells. To clarify the distribution of PTEN within the cell body, we subjected these cells to subcellular fractionation (Fig. $6 N$ ). By Western blotting, PTEN was detected in the nucleus and not in the cytosol. Despite the use of protease inhibitors, the $40,000 \mathrm{Da}$ band, a putative proteolytic product marked with an *, was stronger in CNS stem cells than in PC12 cells. The cytosolic marker $\beta$-tubulin was nearly completely absent from the nuclear fraction. Hence, we reach the same conclusion for CNS stem cells as we did for PC12 cells, namely, substantial nuclear localization for PTEN in neuronal cells.

In this CNS stem cell system, PTEN antisense oligonucleotides decreased the yield of neuronal cells in response to both NGF and BDNF (Fig. 7A, $B$ ). We cannot say for certain whether the PTEN antisense oligonucleotides lower the yield of neuronal cells by inducing cell death. Removal of the EGF triggers substantial apoptosis (Lachyankar et al., 1997) that obscures any additional cell death that might be induced by PTEN antisense oligonucleotides. Removal of EGF also triggers astrocytic differentiation (Fig. 7C). This glial differentiation was not inhibited by PTEN antisense oligonucleotides.

\section{DISCUSSION}

Although PTEN is a well established tumor suppressor for gliomas, this is the first study to analyze PTEN's role in the nervous system. We show here that PTEN is expressed in many adult neurons. For PC12 cells and cultured CNS stem cells, PTEN expression is induced during neuronal differentiation, and suppression of PTEN levels with antisense oligonucleotides decreases the yield of neuronal cells. For PC12 cells, PTEN antisense does not block initiation of differentiation. Instead it leads to the loss of differentiating cells. Finally we do not detect PTEN in glial cells in vivo, indicating that in adult brain glial PTEN expression is at substantially lower levels than is neuronal expression. In vitro we detect weak expression of PTEN in immature
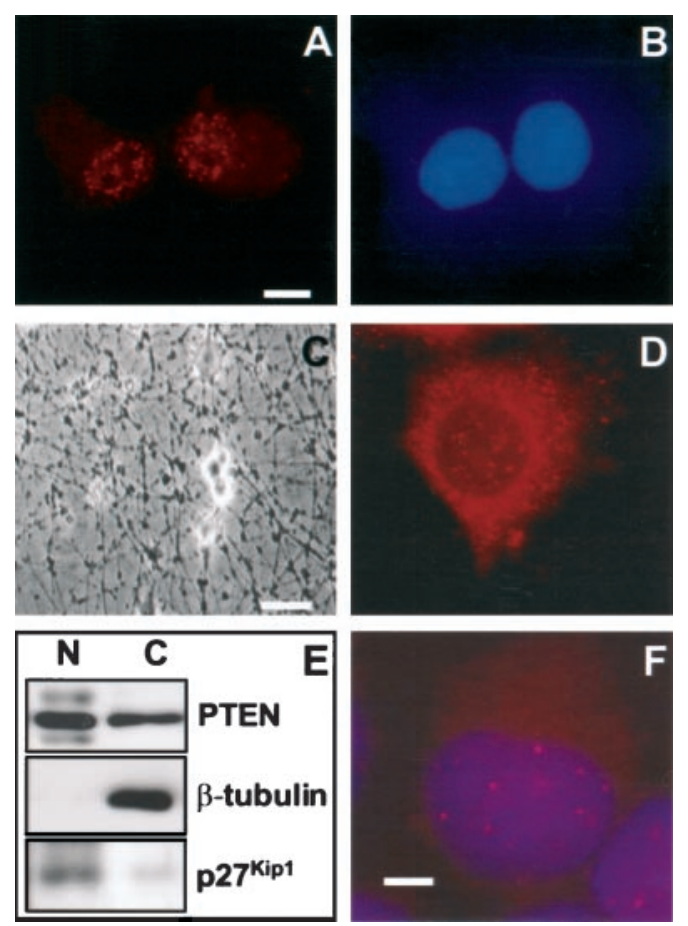

Figure 4. PTEN is present in the nucleus and cytoplasm of PC12 cells. $A, B, \mathrm{PTEN}$ and 4,6-diamidino-2-phenylindole (DAPI) staining of PC12 cells treated with NGF for $6 \mathrm{~d}$. $C, D$, Phase-contrast and PTEN staining of cells treated for $16 \mathrm{~d}$. E, Subcellular fractionation. PC12 cells treated with NGF for $6 \mathrm{~d}$ were separated into nuclear $(N)$ and cytosolic $(C)$ fractions. By Western blotting, PTEN was detected in both nuclear and cytosolic fractions. The nuclear protein $\mathrm{p} 27^{\mathrm{Kip} 1}$ was present in the nuclear fraction. The purity of the nuclear fractions was demonstrated by the virtual exclusion of $\beta$-tubulin. $F$, Double exposure showing subcellular distribution of recombinant PTEN visualized with an anti-HA antibody (red) and DAPI labeling of the nucleus (blue). Scale bars: $A, B, D, 5 \mu \mathrm{m}$; $C, 30 \mu \mathrm{m} ; F, 1 \mu \mathrm{m}$.

astrocytes and find that diminishing PTEN expression does not affect glial differentiation. These results have four important implications. First, PTEN likely regulates PIP levels and PIPdependent functions of mature neurons. Second, PTEN plays a role in neural development, particularly during neurite extension. Third, PTEN's nuclear localization suggests additional regulatory functions as well as a possible signal transduction pathway. Fourth, the absence of PTEN expression in mature astrocytes is consistent with recent proposals that gliomas are derived from astrocytic precursors.

\section{PTEN in brain neurons}

The strong expression of PTEN in neurons compared with the lack of detectable expression in adult astrocytes may be at least partly explained by the distribution of phosphoinositide- 3 kinase. PIP levels are critical to cell survival. Both very low PIP levels (Datta et al., 1997) and very high PIP levels (Klippel et al., 1998) can result in cell death. Phosphoinositide-3 kinase and PTEN have opposing roles in regulating PIP levels. Hence, one would predict that phosphoinositide-3 kinase-expressing cells would also express PTEN and that phosphoinositide-3 kinase-deficient cells would have little or no PTEN. The $85 \mathrm{kDa}$ regulatory subunit (p55 $\alpha, \mathrm{p} 55 \gamma, \mathrm{p} 85 \alpha, \mathrm{p} 85 \beta$, and $\mathrm{p} 50 \alpha$ isoforms) and the $110 \mathrm{kDa}$ catalytic subunit ( $\alpha$ isoform) of phosphoinositide-3 kinase are strongly expressed in neurons but not detected in glial cells (Folli et al., 1994; Ito et al., 1995; Shin et al., 1998). A caveat in this 
A
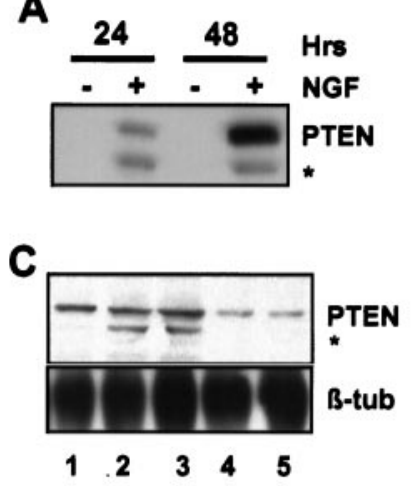

D
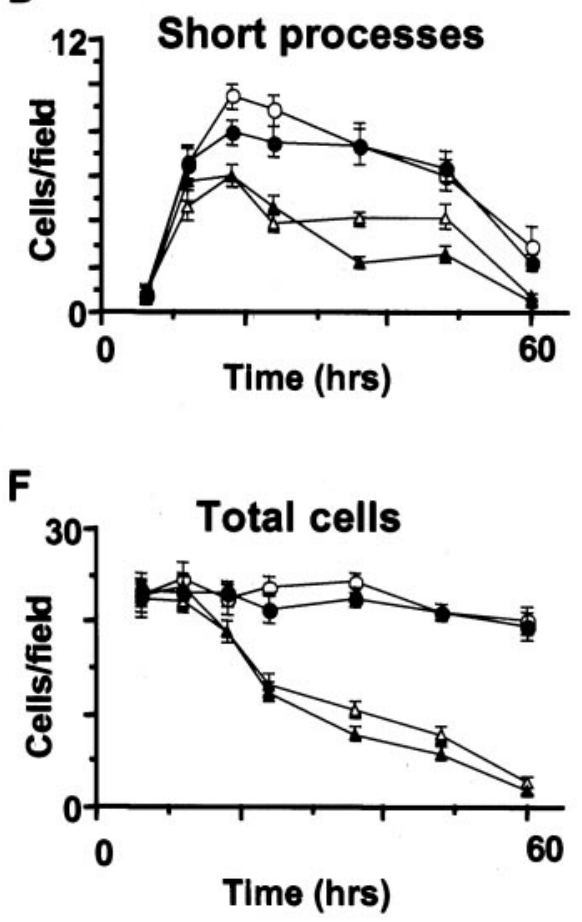

B

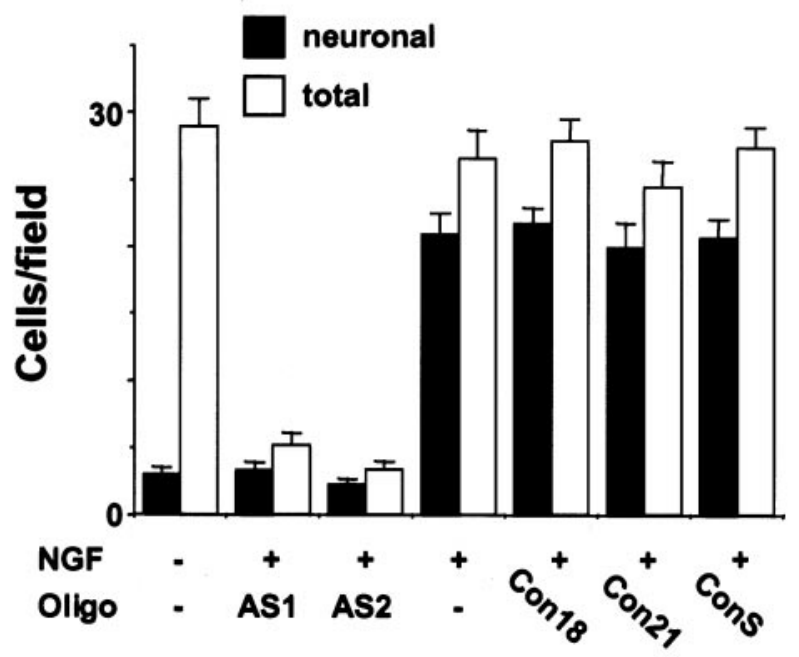

\section{E}

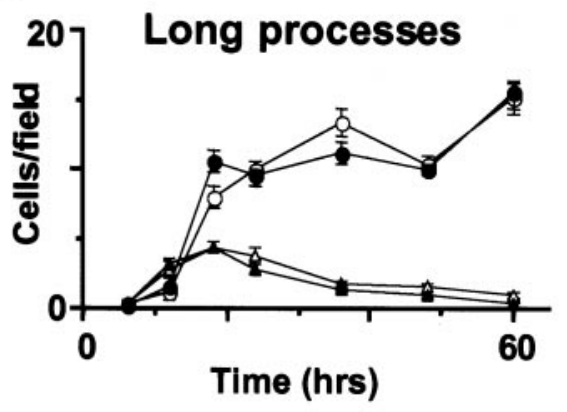

Figure 5. Suppression of PTEN expression lowers the yield of differentiated PC12 cells. $A$, PC12 cells in defined medium were treated with or without NGF. Induction of PTEN was measured by Western blotting. A putative proteolytic derivative of PTEN is marked with an *. B, PTEN antisense oligonucleotides (Oligo) AS1 and AS2 or control oligonucleotides Con18, Con21, and ConS were included in some cultures. These cultures were scored after $60 \mathrm{hr}$ of treatment. Means $( \pm$ SEM) are reported for cells per field and cells with neurites at least 5 cell diameters long per field. $C$, Western blot $(50 \mu \mathrm{g}$ of protein per lane) shows suppression of PTEN expression. Samples were collected after 40 $\mathrm{hr}$ of treatment, which in this particular experiment preceded substantial cell death. $\beta$-tub, $\beta$-Tubulin. Lane 1, NGF + Con18; lane 2, NGF + Con21; lane 3, NGF + ConS; lane 4, NGF + AS1; lane 5, NGF + AS2. $D-F$, PC12 cells in defined medium were treated with NGF and control or PTEN antisense oligonucleotides. $D$, Cells with short neurites (1-2 cell diameters) per field are reported as means $( \pm$ SEM). $E$, Cells with longer neurites ( 3 or more cell diameters) per field are shown. $F$, Total cells per field are shown. argument is that the relative distribution of the $110 \mathrm{kDa}$ subunit $\beta$ isoform has not yet been determined. Despite this omission, PTEN and phosphoinositide-3 kinase appear to have similar expression patterns in the brain; both are strongly expressed in Purkinje cells and pyramidal neurons of the cortex and are not detected in astrocytes and oligodendrocytes.

We do not know which functions in adult neurons are regulated by PTEN, but certainly the known PIP-dependent functions are good candidates. PIPs increase $\mathrm{Ca}^{2+}$ channel activity, thereby affecting neurotransmitter release, gene expression, and survival (Blair and Marshall, 1997; Blair et al., 1999; Hardingham et al., 1999; Hu et al., 1999). PIPs also potentiate electrical activity and increase modulation by neuropeptides (Yang and Raizada, 1999). In a variety of cell systems, PIPs increase sugar uptake and metabolism (Frevert and Kahn, 1997), which would be helpful to sustain increased electrical activity. After injury, PIPs enhance neuronal survival, sprouting, and regeneration (Kobayashi et al., 1997). Further studies are required to test each of these candidates and also to determine whether PTEN's protein phosphatase activity plays a role in adult neurons.

\section{Role of PTEN in neuronal development}

We describe a series of experiments to demonstrate the role of PTEN in neuronal differentiation. Western blotting of brain 

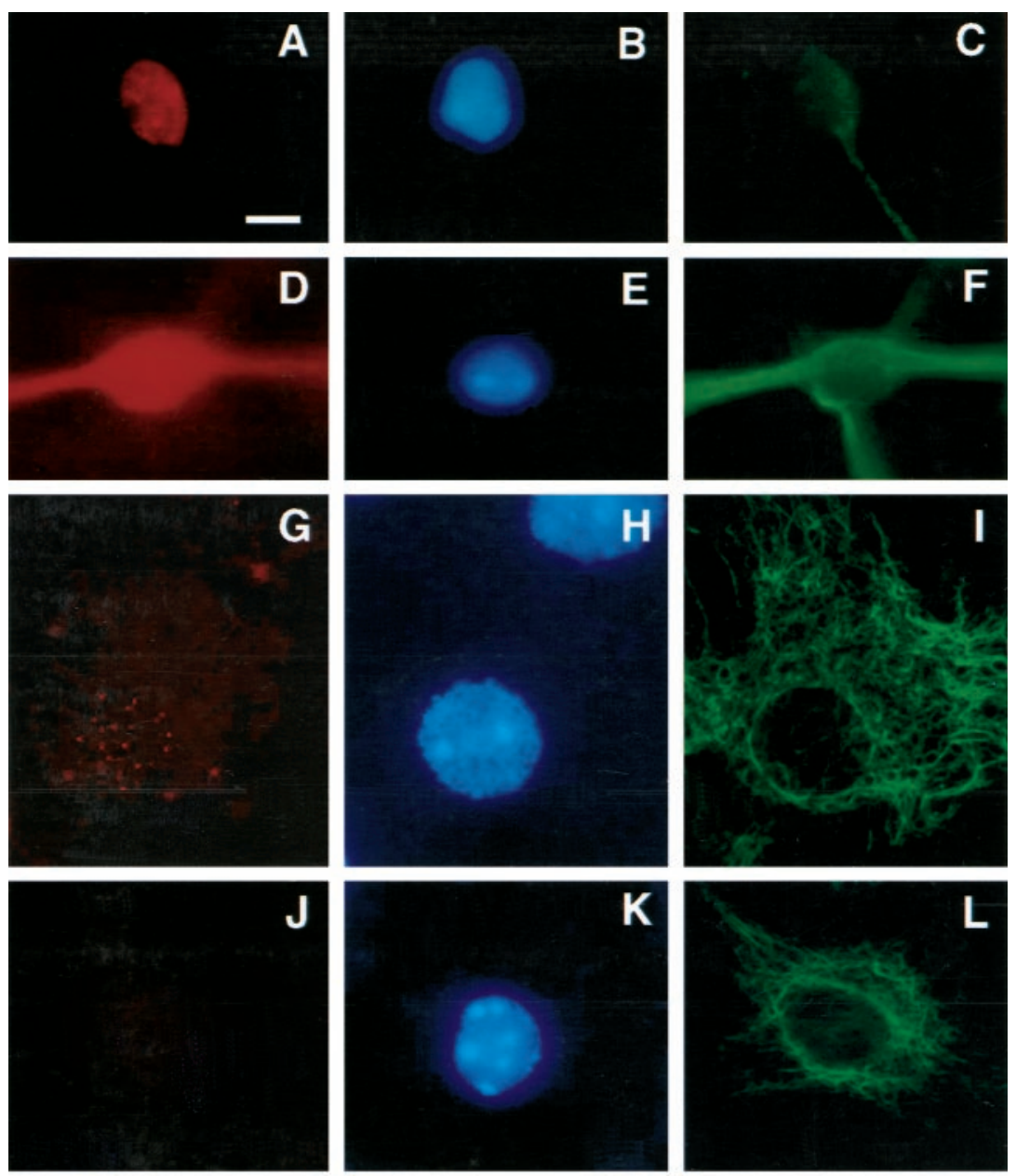

stem cells. Cultures were treated with BDNF for $6 \mathrm{~d}$ $(A-C, G-I, M)$ or $14 \mathrm{~d}(D-F, J-L) . A, D, G, J$, AntiPTEN. $B, E, H, K$, DAPI staining of nuclei. $C, F$, Anti$\beta$-tubulin III. I, $L$, Anti-GFAP. PTEN is detected in immature and mature neuronal cells but is detected only in immature astrocytic cells. $M$, Induction of PTEN by BDNF ( $6 \mathrm{~d}$ of treatment) by Western blotting. For both of these samples, EGF was omitted, so the - BDNF cultures contained immature astrocytes and the +BDNF cultures contained both neuronal cells and immature astrocytes. $N$, Cultures treated with BDNF for $6 \mathrm{~d}$, resulting in both neuronal and astroglial PTEN-positive cells, and subjected to subcellular fractionation, revealing a nuclear localization. Scale bar: $A-L, 5 \mu \mathrm{m}$.
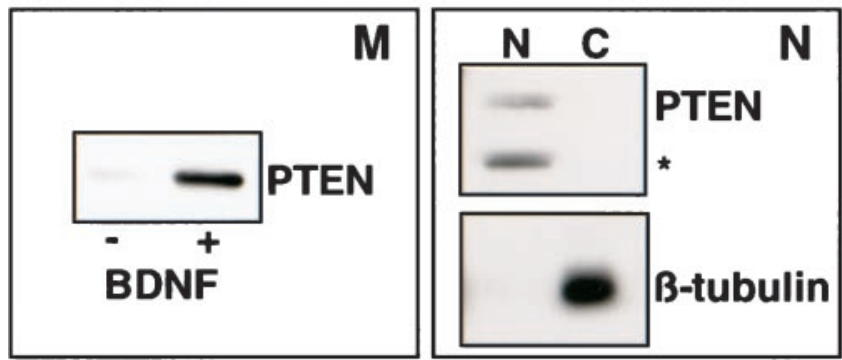

extracts shows that PTEN expression is first detected at approximately P0, relatively late in neuronal development. For PC12 cells, PTEN expression is induced by NGF and lags behind the initial neurite extension. PTEN appears during elongation of the nascent neurites, perhaps consistent with the report that PIPs regulate neurite elongation (Kimura et al., 1994). PC12 cells with short neurites, but only very few mature neuronal cells, are observed for NGF-treated PC12 cells in the presence of PTEN antisense oligonucleotides. These results demonstrate that PTEN is expressed during neurite extension, and suppression of PTEN expression leads to the loss of these maturing, neuronal cells.

Differentiating neuronal cells appear to be unique in their requirement for PTEN. Murine fibroblasts lacking PTEN genes are actually resistant to apoptotic stimuli (Stambolic et al., 1998). In this study, proliferating PC12 cells and CNS stem cells express little or no PTEN and are not sensitive to PTEN antisense. Therefore, the most likely explanation is that PTEN regulates an important step during neurotrophin-induced neuronal differentiation. It has been suggested that PTEN plays a role in cell cycle arrest, perhaps by induction of the cyclin-dependent kinase inhibitor p27 $7^{\mathrm{Kip} 1}$ ( $\mathrm{Li}$ and Sun, 1998). Suppression of PTEN expression might result in initiation of differentiation without cell cycle arrest, thereby triggering apoptosis (Shi et al., 1994). This is apparently not the case because blocking cell proliferation with recombinant $\mathrm{p} 21^{\mathrm{WAF} 1}$ does not rescue the cells (data not shown). Another possibility is that suppression of PTEN expression leads to excess PIPs and aberrant neurite extension. We have tested this possibility by treating PC12 cells with the phosphoinositide- 3 kinase inhibitors LY294002 and wortmannin. These drugs do not rescue the antisense-treated cells. However, the interpretation of this experiment is complex; it is plausible that these drugs do not restore correct PIP levels. Hence, further experiments are required to elucidate the mechanism by which PTEN antisense induces cell death. 

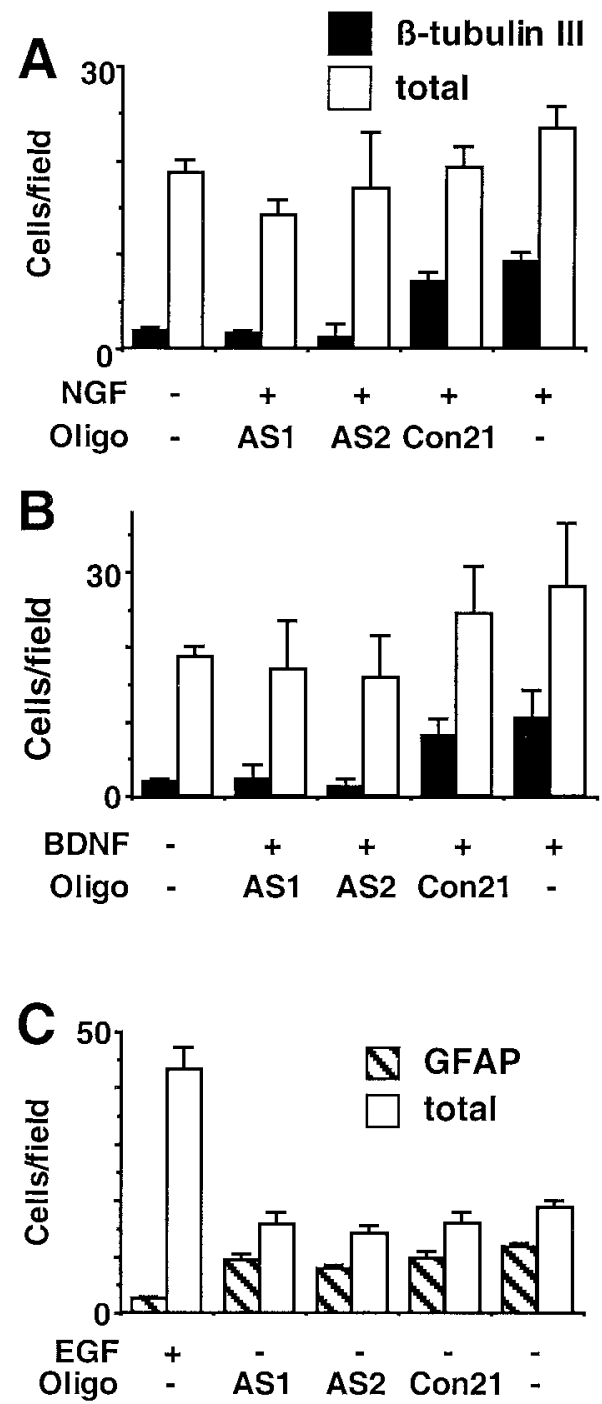

Figure 7. Suppression of PTEN expression decreases the yield of neuronal cells but not astrocytes. $A$, CNS stem cell cultures were treated with or without NGF and oligonucleotides and scored for neuronal cells ( $\beta$-tubulin III). NGF-induced neuronal differentiation was suppressed by PTEN antisense but not control oligonucleotide Con21. The mean number of cells $( \pm$ SEM) per field is shown. $B$, BDNF-induced neuronal differentiation also was suppressed by PTEN antisense. $C$, Astrocytic differentiation was induced by removal of the mitogen EGF. PTEN antisense had no apparent effect on astrocytic differentiation.

\section{Detection of PTEN in the nucleus}

As judged by immunofluorescence microscopy and subcellular fractionation, PTEN is both nuclear and cytoplasmic. In addition, PC12 cells transfected with a PTEN expression vector showed nuclear localization. In previous studies (Li and Sun, 1997; Gu et al., 1998), PTEN exogenously expressed in hepatocellular carcinoma and fibroblast cells was cytoplasmic. This apparent disagreement may be caused by a cell type-specific distribution for PTEN. The detection of PTEN in both the nucleus and cytoplasm is reminiscent of a number of signaling molecules. MAP kinases (Cahill et al., 1996), the Akt kinase (Andjelkovic et al., 1997; Meier et al., 1997), and $\beta$-catenin (Willert and Nusse, 1998) show this dual distribution. An important question for future study is whether external stimuli modulate the levels and/or activity of nuclear PTEN and, thereby, regulate nuclear function.
The role of PTEN in the nucleus may relate to the widely documented, but poorly understood, nuclear PIP cycle. Nuclear PIPs are detected both by immunohistochemical techniques and by chemical analysis of nuclear extracts (Mazzotti et al., 1995; Caramelli et al., 1996; Boronenkov et al., 1998; Lu et al., 1998). Phosphoinositide-3 kinase (Zini et al., 1996; Boronenkov et al., 1998; Lu et al., 1998) and the PIP-specific phospholipase C $\beta$ (Manzoli et al., 1997; Sun et al., 1997; Neri et al., 1998) are detected in the nucleus. Treatment of PC12 cells with NGF induces activation and nuclear translocation of phosphoinositide-3 kinase (Neri et al., 1994), and nuclear PIP3 might regulate the activities of plekstrin homology domain-containing proteins. For example Akt is activated at the plasma membrane and then translocates to the nucleus (Andjelkovic et al., 1997; Meier et al., 1997). A PIPbinding protein abundant in brain was recently reported to be targeted to the nucleus (Tanaka et al., 1999). Hence, by hydrolyzing nuclear PIPs, PTEN may regulate a number of nuclear proteins and functions.

\section{Role of PTEN in the development of gliomas}

The lack of detectable PTEN expression in adult astrocytes raises the intriguing question of how PTEN can influence development of glial tumors. The critical point in developing such a scheme is the identity of the glioma progenitor cell. Although older models proposed that gliomas result from dedifferentiated astrocytes, it recently has been suggested that gliomas are transformed glial precursor cells (Noble and Mayer-Proschel, 1997; Holland et al., 1998). We did detect weak expression of PTEN in immature astrocytic cells differentiating in vitro. Hence, important questions for future studies include whether glial precursor cells in vivo also are PTEN positive and whether loss of PTEN, perhaps combined with other genetic lesions, initiates excess cell proliferation. The availability of mouse models will provide answers to these questions as well as an experimental system to develop new therapeutic approaches for gliomas.

\section{REFERENCES}

Ahmed S, Reynolds BA, Weiss S (1995) BDNF enhances the differentiation but not the survival of CNS stem cell-derived neuronal precursors. J Neurosci 15:5765-5778.

Andjelkovic M, Alessi DR, Meier R, Fernandez A, Lamb NJC, Frech M, Cron P, Cohen P, Lucocq JM, Hemmings BA (1997) Role of translocation in the activation and function of protein kinase B. J Biol Chem 272:31515-31524.

Blair LAC, Marshall J (1997) IGF-1 modulates N and L calcium channels in a PI 3-kinase-dependent manner. Neuron 19:421-429.

Blair LAC, Bence-Hanulec KK, Mehta S, Franke T, Kaplan D, Marshall J (1999) Akt-dependent potentiation of $\mathrm{L}$ channels by insulin-like growth factor-1 is required for neuronal survival. J Neurosci 19:1940-1951.

Boronenkov IV, Loijens JC, Umeda M, Anderson RA (1998) Phosphoinositide signaling pathways in nuclei are associated with nuclear speckles containing pre-mRNA processing factors. Mol Biol Cell 9:3547-3560.

Cahill MA, Janknecht R, Nordheim A (1996) Signalling pathways: jack of all cascades. Curr Biol 6:16-19.

Caramelli E, Matteucci A, Zini N, Carini C, Guidotti L, Ricci D, Maraldi NM, Capitani S (1996) Nuclear phosphoinositide-specific phospholipase C, phosphatidylinositol 4,5-bisphosphate and protein kinase $\mathrm{C}$ during rat spermatogenesis. Eur J Cell Biol 71:154-164.

Datta SR, Dudek H, Tao X, Masters S, Fu H, Gotoh Y, Greenberg ME (1997) Akt phosphorylation of BAD couples survival signals to the cell-intrinsic death machinery. Cell 91:231-241.

Di Cristofano A, Pesce B, Cordon-Cardo C, Pandolfi PP (1998) Pten is essential for embryonic development and tumour suppression. Nat Genet 19:348-355. 
Di Cristofano A, Kotsi P, Peng YF, Cordon-Cardo C, Elkon KB, Pandolfi PP (1999) Impaired Fas response and autoimmunity in $P T E N^{+/-}$ mice. Science 285:2122-2125.

Eng C, Murday V, Seal S, Mohammed S, Hodgson SV, Chardary MA, Fentiman IS, Ponder BAJ, Eeles RA (1994) Cowden syndrome and Lhermitte-Duclos disease in a family: a single genetic syndrome with pleiotropy? J Med Genet 31:458-461.

Folli F, Bonfanti L, Renard E, Kahn CR, Merighi A (1994) Insulin receptor substrate-1 (IRS-1) distribution in the rat central nervous system. J Neurosci 14:6412-6422.

Frevert EU, Kahn BB (1997) Differential effects of constitutively active phosphatidylinositol 3-kinase on glucose transport, glycogen synthase activity, and DNA synthesis in 3T3-L1 adipocytes. Mol Cell Biol 17:190-198.

Furnari FB, Huang H-JS, Cavenee WK (1998) The phosphoinositol phosphatase activity of PTEN mediates a serum-sensitive $\mathrm{G}_{1}$ growth arrest in glioma cells. Cancer Res 58:5002-5008.

Gollapudi L, Neet KE (1997) Different mechanisms for inhibition of cell proliferation via cell cycle proteins in PC12 cells by nerve growth factor and staurosporine. J Neurosci Res 49:461-474.

Gorlin RJ, Cohen MM, Condon LM, Burke BA (1992) Bannayan-RileyRuvalcaba syndrome. Am J Med Genet 44:307-314.

Gu J, Tamura M, Yamada KM (1998) Tumor suppressor PTEN inhibits integrin- and growth factor-mediated mitogen-activated protein (MAP) kinase signaling pathways. J Cell Biol 143:1375-1383.

Hardingham GE, Chawla S, Cruzalegui FH, Bading H (1999) Control of recruitment and transcription-activating function of CBP determines gene regulation by NMDA receptors and L-type calcium channels. Neuron 22:789-798.

Holland EC, Hively W P, DePinho RA, Varmus HE (1998) A constitutively active epidermal growth factor receptor cooperates with disruption of $\mathrm{G}_{1}$ cell-cycle arrest pathways to induce glioma-like lesions in mice. Genes Dev 12:3675-3685.

Hu S-C, Chrivia J, Ghosh A (1999) Regulation of CBP-mediated transcription by neuronal calcium signaling. Neuron 22:799-808.

Ito Y, Goto K, Kondo H (1995) Localization of mRNA for phosphatidylinositol 3-kinase in brain of developing and mature rats. Mol Brain Res 34:149-153.

Kimura K, Hattori S, Kabuyama Y, Shizawa Y, Takayanagi J, Nakamura S, Toki S, Matsuda Y, Onodera K, Fukui Y (1994) Neurite outgrowth of PC12 cells is suppressed by wortmannin, a specific inhibitor of phosphatidylinositol 3-kinase. J Biol Chem 269:18961-18967.

Klippel A, Escobedo M-A, Wachowicz MS, Apell G, Brown TW, Giedlin MA, Kavanaugh WM, Williams LT (1998) Activation of phosphatidylinositol 3-kinase is sufficient for cell cycle entry and promotes cellular changes characteristic of oncogenic transformation. Mol Cell Biol 18:5699-5711.

Kobayashi M, Nagata S, Kita Y, Nakatsu N, Ihara S, Kaibuchi K, Kuroda S, Ui M, Iba H, Konishi H, Kikkawa U, Saitoh I, Fukui Y (1997) Expression of a constitutively active phosphatidylinositol 3-kinase induces process formation in rat $\mathrm{PC12}$ cells. J Biol Chem 272:16089-16092.

Lachyankar MB, Condon PJ, Quesenberry PJ, Litofsky NS, Recht LD, Ross AH (1997) Embryonic precursor cells that express Trk receptors: induction of different cell fates by NGF, BDNF, NT-3, and CNTF. Exp Neurol 144:350-360.

Li D-M, Sun H (1997) TEP1, encoded by a candidate tumor suppressor locus, is a novel protein tyrosine phosphatase regulated by transforming growth factor $\beta$. Cancer Res 57:2124-2129.

Li D-M, Sun H (1998) PTEN/MMAC1/TEP1 suppresses the tumorigenicity and induces $\mathrm{G}_{1}$ cell cycle arrest in human glioblastoma cells. Proc Natl Acad Sci USA 95:15406-15411.

Li J, Yen C, Liaw D, Podsypanina K, Bose S, Wang SI, Puc J, Miliaresis C, Rodgers L, McCombie R, Bigner SH, Giovanella BC, Ittmann M, Tycko B, Hibshoosh H, Wigler MH, Parsons R (1997) PTEN, a putative protein tyrosine phosphatase gene mutated in human brain, breast, and prostate cancer. Science 275:1943-1947.

Liaw D, Marsh DJ, Li J, Dahia PLM, Wang SI, Zheng Z, Bose S, Call KM, Tsou HC, Peacocke M, Eng C, Parsons R (1997) Germline mutations of the PTEN gene in Cowden disease, an inherited breast and thyroid cancer syndrome. Nat Genet 16:64-67.

Lu P-J, Hsu A-L, Wang D-S, Yan HY, Yin HL, Chen C-S (1998) Phosphoinositide 3-kinase in rat liver nuclei. Biochemistry 37:5738-5745.

Maehama T, Dixon JE (1998) The tumor suppressor, PTEN/MMAC1, dephosphorylates the lipid second messenger, phosphatidylinositol 3,4,5-triphosphate. J Biol Chem 273:13375-13378.

Manzoli L, Billi AM, Rubbini S, Bavelloni A, Faenza I, Gilmour RS, Rhee S-G, Cocco L (1997) Essential role for nuclear phospholipase C $\beta_{1}$ in insulin-like growth factor I-induced mitogenesis. Cancer Res 57:2137-2139.

Mazzotti G, Zini N, Rizzi E, Rizzoli R, Galanzi A, Ognibene A, Santi S, Matteucci A, Martelli AM, Maraldi NM (1995) Immunocytochemical detection of phosphatidylinositol 4,5-bisphosphate localization sites within the nucleus. J Histochem Cytochem 43:181-191.

Meier R, Alessi DR, Cron P, Andjelkovic M, Hemmings BA (1997) Mitogenic activation, phosphorylation, and nuclear translocation of protein kinase B $\beta$. J Biol Chem 272:30491-30497.

Myers MP, Stolarov JP, Eng C, Li J, Wang SI, Wigler MH, Parsons R, Tonks NK (1997) P-TEN, the tumor suppressor from human chromosome $10 \mathrm{q} 23$, is a dual-specificity phosphatase. Proc Natl Acad Sci USA 94:9052-9057.

Myers MP, Pass I, Batty IH, Van der Kaay J, Stolarov JP, Hemmings BA, Wigler MH, Downes CP, Tonks NK (1998) The lipid phosphatase activity of PTEN is critical for its tumor suppressor function. Proc Natl Acad Sci USA 95:13513-13518.

Neri LM, Milani D, Bertolaso L, Stroscio M, Bertagnolo V, Capitani S (1994) Nuclear translocation of phosphatidylinositol 3-kinase in rat pheochromocytoma PC12 cells after treatment with nerve growth factor. Cell Mol Biol 40:619-626.

Neri LM, Borgatti P, Capitani S, Martelli AM (1998) Nuclear diacylglycerol produced by phosphoinositide-specific phospholipase $\mathrm{C}$ is responsible for nuclear translocation of protein kinase C- $\alpha$. J Biol Chem 273:29738-29744.

Noble M, Mayer-Proschel M (1997) Growth factors, glia and gliomas. J Neurooncol 35:193-209.

Ohmori Y, Schreiber RD, Hamilton TA (1997) Synergy between interferon- $\gamma$ and tumor necrosis factor- $\alpha$ in transcriptional activation is mediated by cooperation between signal transducer and activator of transcription 1 and nuclear factor $\kappa$ B. J Biol Chem 272:14899-14907.

Poluha W, Poluha DK, Chang B, Crosbie NE, Schonhoff CM, Kilpatrick DL, Ross AH (1996) The cyclin-dependent kinase inhibitor p21 WAF1 is required for survival of differentiating neuroblastoma cells. Mol Cell Biol 16:1335-1341.

Poluha W, Schonhoff CM, Harrington KS, Lachyankar MB, Crosbie NE, Bulseco DA, Ross AH (1997) A novel, nerve growth factor-activated pathway involving nitric oxide, p53, and $\mathrm{p} 21^{\mathrm{WAF} 1}$ regulates neuronal differentiation of PC12 cells. J Biol Chem 272:24002-24007.

Reinhold DS, Neet KE (1989) The lack of a role for protein kinase C in neurite extension and in the induction of ornithine decarboxylase by nerve growth factor in PC12 cells. J Biol Chem 264:3538-3544.

Reynolds BA, Weiss S (1992) Generation of neurons and astrocytes from isolated cells of the adult mammalian central nervous system. Science 255:1707-1710.

Reynolds BA, Tetzlaff W, Weiss S (1992) A multipotent EGFresponsive striatal embryonic progenitor cell produces neurons and astrocytes. J Neurosci 12:4565-4574.

Shaw G, Weber K (1982) Differential expression of neurofilament triplet proteins in brain development. Nature 298:277-279.

Shi L, Nishioka WK, Th'ng J, Bradbury EM, Litchfield DW, Greenberg AH (1994) Premature p34cdc2 activation required for apoptosis. Science 263:1143-1145.

Shin B-C, Suzuki M, Inukai K, Anai M, Asano T, Takata K (1998) Multiple isoforms of the regulatory subunit for phosphatidylinositol 3-kinase (PI3-kinase) are expressed in neurons in the rat brain. Biochem Biophys Res Commun 246:313-319.

Stambolic V, Suzuki A, Lois de la Pompa J, Brothers GM, Mirtsos C, Sasaki T, Ruland J, Penninger JM, Siderovski DP, Mak TW (1998) Negative regulation of PKB/Akt-dependent cell survival by the tumor suppressor PTEN. Cell 95:29-39.

Steck PA, Pershouse MA, Jasser SA, Yung WKA, Lin H, Ligon AH, Langford LA, Baumgard ML, Hattier T, Davis T, Frye C, Hu R, Swedlund B, Teng DHF, Tavtigian SV (1997) Identification of a candidate tumour suppressor gene, $M M A C 1$, at chromosome 10q23.3 that is mutated in multiple advanced cancers. Nat Genet 15:356-362.

Stein CA (1996) Phosphorothioate antisense oligodeoxynucleotides: questions of specificity. Trends Biotechnol 14:147-149. 
Sun B, Murray NR, Fields AP (1997) A role for nuclear phosphatidylinositol-specific phospholipase $\mathrm{C}$ in the $\mathrm{G}_{2} / \mathrm{M}$ phase transition. J Biol Chem 272:26313-26317.

Suzuki A, de la Pompa JL, Stambolic V, Elia AJ, Sasaki T, del Barco Barrantes I, Ho A, Wakeham A, Itie A, Khoo W, Fukumoto M, Mak TW (1998) High cancer susceptibility and embryonic lethality associated with mutation of the PTEN tumor suppressor gene in mice. Curr Biol 8:1169-1178.

Tamura M, Gu J, Matsumoto K, Aota S, Parsons R, Yamada KM (1998) Inhibition of cell migration, spreading, and focal adhesions by tumor suppressor PTEN. Science 280:1614-1617.

Tanaka K, Horiguchi K, Yoshida T, Takeda M, Fujisawa H, Takeuchi K, Umeda M, Kato S, Ihara S, Nagata S, Fukui Y (1999) Evidence that a phosphatidylinositol 3,4,5-triphosphate-binding protein can function in nucleus. J Biol Chem 274:3919-3922.

Willert K, Nusse R (1998) Beta-catenin: a key mediator of Wnt signaling. Curr Opin Genet Dev 8:95-102.

Yang H, Raizada MK (1999) Role of phosphatidylinositol 3-kinase in angiotensin II regulation of norepinephrine neuromodulation in brain neurons of the spontaneously hypertensive rat. J Neurosci 19:2413-2423.

Zini N, Ognibene A, Bavelloni A, Santi S, Sabatelli P, Baldini N, Scotlandi K, Serra M, Maraldi NM (1996) Cytoplasmic and nuclear localization sites of phosphatidylinositol 3-kinase in human osteosarcoma sensitive and multidrug-resistant Saos-2 cells. Histochem Cell Biol 106:457-464 